\title{
Robust optimisation of coastal environmental impact from oil spills using a flexible evolution agent and finding the optimal course of the damaged tanker
}

\author{
B. González, B. Galván, E. Benítez, I. Martín, J. P. Ramos, \\ H. Carmona \& G. Winter \\ Laboratory of Evolutionary Computation and Applications (CEANI), \\ Institute of Intelligent Systems and Numerical Applications in \\ Engineering (IUSIANI), University of Las Palmas de Gran Canaria, \\ Spain
}

\begin{abstract}
We present a methodology that attempts to help spill decision responders select appropriate response options to minimize coastal environmental impacts when a tanker leaks oil into the sea. For example, which direction should the tanker head for - towards the open sea or a coastal area where the oil slick can be concentrated and picked up more easily? In this context, CEANI is developing a useful integrated decision-making on-line system for fast response in emergency situations named the Alermac System, incorporating the present methodology presented here. The main targets of the ALERMAC project are the validation of data processing and on-line transmission from buoys, and the validation of a friendly and robust control system together with integrated simulation and risk assessment tools for decision-making in the rapid response required in emergency situations so as to minimize the environmental and socio-economic impact of marine spills. In order to solve this optimization problem, we use Evolutionary Intelligent Agent-based software named Flexible Evolution Agent (FEA), in a context of robust design optimisation.
\end{abstract}

Keywords: oil spill, environmental impact, decision-making on-line system, robust design optimization. 


\section{Introduction}

The ALERMAC project [5, 6] designs, validates and provides an integrated network with an on-line system of monitoring, alert and risk management of oil spills and catastrophic incidents in the Macaronesian maritime zone. The system is made up of an alert and surveillance network together with a network for the early intervention and mitigation of toxic spills. The alert and surveillance network will detect and monitor oil spills and other toxic substances by means of special sensors installed on new floating autonomous buoys, which will transmit the data to the control system. Simulation software for the evolution of spills in the sea, as well as risk assessment software has been incorporated into this system (see Figs. 1 and 2).

The project is being carried out in collaboration with the Las Palmas, Tenerife, Madeira and Cabo Verde Port Authorities. The buoys which will be placed at different points of the Macaronesian zone for field data capture were designed by the Canary Island Institute of Marine Sciences (ICCM).

\section{COMPREHENSIVE SOLUTION TO THE EFFECTIVE MONITORING ALERMA OF CONTAMINANTS AND DISASTER RISK MANAGEMENT IN THE MACARONESIAN MARITIME ZONE}

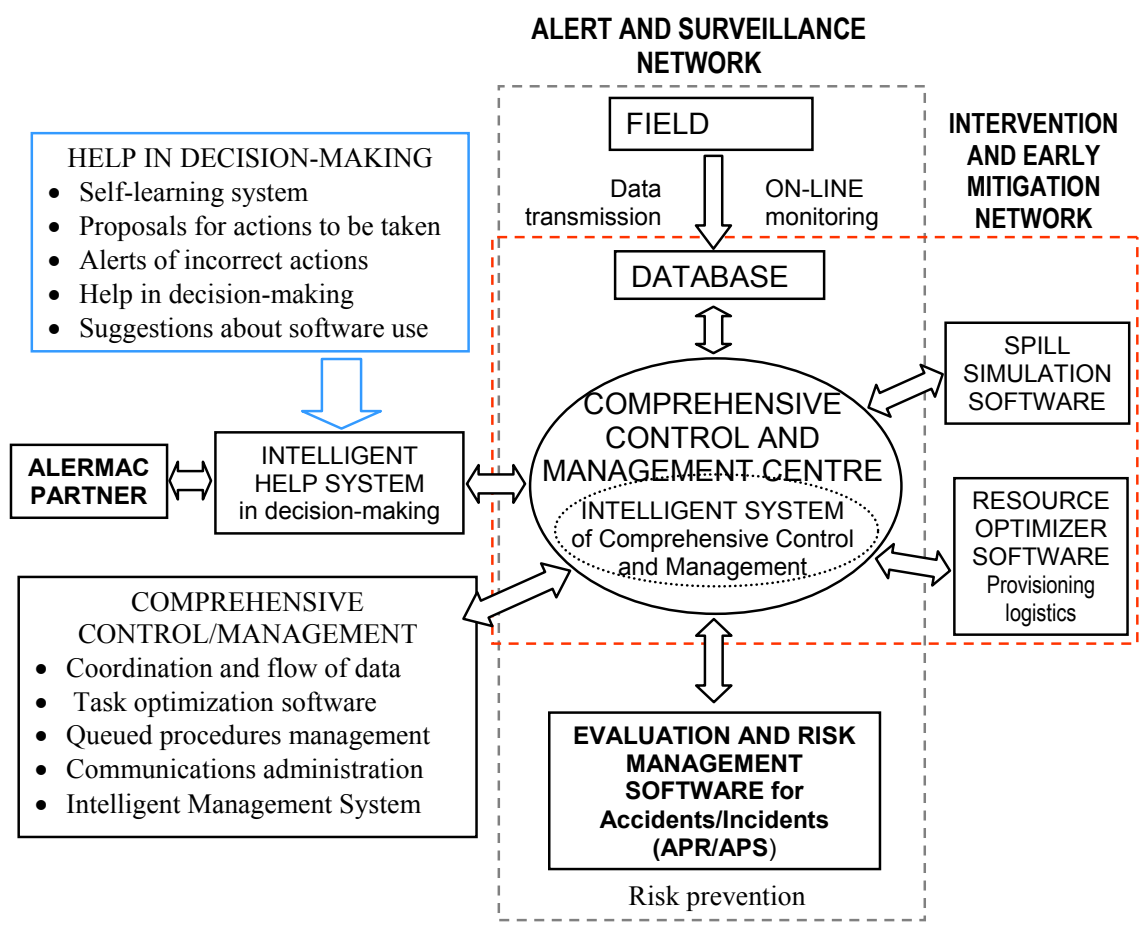

Figure 1: Alermac system's scheme. 


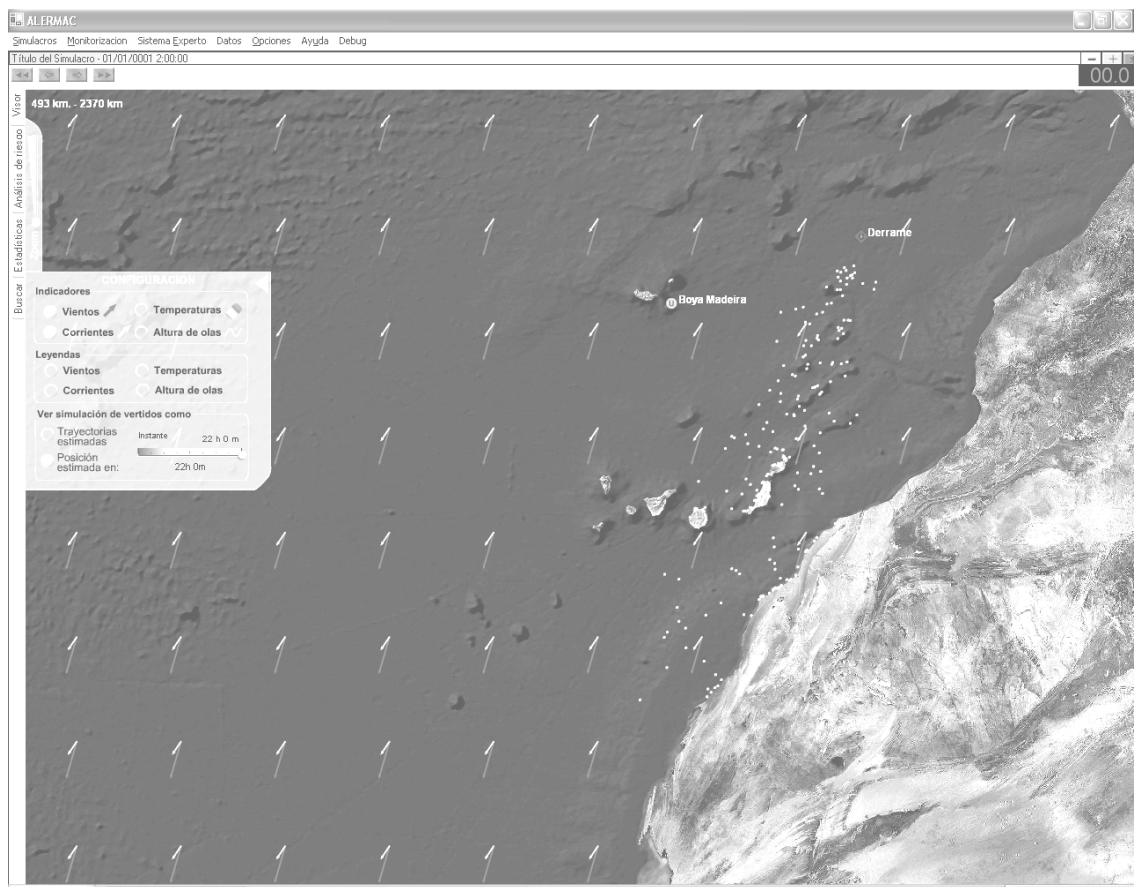

Figure 2: Alermac System's user environment.

In CEANI, software named Slick has been designed to help spill responders select appropriate response options to minimize coastal environmental impacts in the event of oil spills, has been designed [7], which mainly consists of three programmes which simulate the oil slick path, weathering and the oil slick-coast interaction. With respect to the oil slick path, a Lagrangian model has been implemented, in which a drift angle for the slick has been incorporated (between $0^{\circ}$ and $13^{\circ}$ in accordance with field and laboratory experiments and previous oil spill data [8]) which is randomly generated for each time step in the execution of the software. As for the spreading of the oil slick, random speeds are determined with a uniform distribution proportional to the diffusion coefficients provided by Fay's formula [9] - with the constant $k_{2}=0.725$ (value recommended by Flores et al. [10]) - and the relation between the coefficients of diffusion and the fluctuation intervals of the speeds given by Leitão [11]. The random speeds are determined as proposed by Proctor et al. [12].

With regards to the question of weathering, new methodology from Fingas [13] and Fingas and Fieldhouse [14] to evaluate the rate of evaporation and the quantitative prediction of emulsification in the slick has been incorporated.

The length of the shoreline contaminated by oil slicks transported in the nearshore environment is evaluated following the work from Law et al. [15].

In this paper we propose a way to optimize the course of a hypothetical damaged tanker in the sea so that the coastal environmental impact is minimum. In this way, the decision variable considered is the course (direction) to be 
considered by the damaged tanker. The wind module and wind direction angle, the variability of the current module and current direction angle have been considered as variables with uncertainties.

\section{Robust design optimization}

If the exact value of some input parameters is unknown, for example, the wind and current direction and module in Environmental Problems, the aim of the robust design optimization is to try to look for solutions that are insensitive or only slightly sensitive to small fluctuations in the input parameters.

When there exists the presence of fluctuations in the operating conditions, it is important to define the stability of a solution because a traditional optimization approach could tend to a problem of "over-optimization", giving a high performance corresponding to the design point, but with poor off-design characteristics (see Fig. 3).

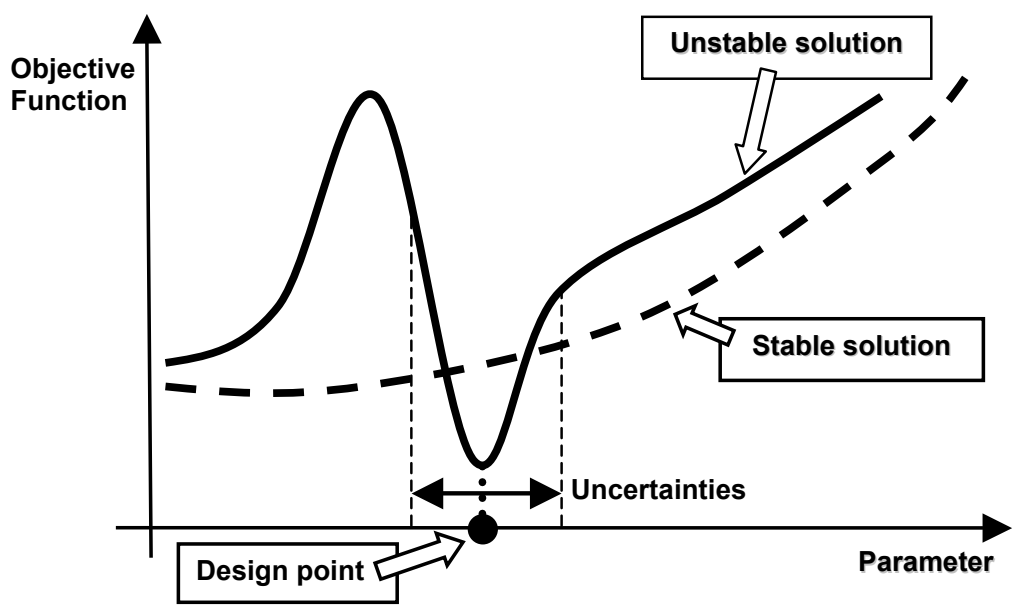

Figure 3: Stable solution versus unstable solution in the neighborhood of a design point.

The following equations represent the mean value (performance) and the variance (stability) of the function to be optimized by the Robust Design approach:

$$
\begin{gathered}
\bar{f}(\bar{x})=\frac{\sum_{n=1}^{N} f_{n}}{N} \\
\sigma^{2}(\bar{x})=\sum_{n=1}^{N} \frac{\left(f_{n}-\bar{f}\right)^{2}}{N-1}
\end{gathered}
$$


With regard to the optimisation problem as considered in this paper, the uncertain parameters in the Robust Design are the wind direction angle, the wind velocity, the variability of the current direction angle and the variability of the current velocity (see Table 1 ). The objective functions to be minimized are the mean of the lengths of coast affected by the oil slick, $\bar{f}(\bar{x})$, evaluated with our software Slick, and the respective standard deviation $\sigma(\bar{x})$.

Table 1: $\quad$ Variables of the problem. $\sigma$ represents the uncertain parameters in the robust design.

\begin{tabular}{|l|c|c|c|c|}
\hline Variable & Distribution & $\begin{array}{c}\text { Lower } \\
\text { Bound }\end{array}$ & $\begin{array}{c}\text { Upper } \\
\text { Bound }\end{array}$ & $\begin{array}{c}\text { Mean Value } \\
(\text { FEA })\end{array}$ \\
\hline$\sigma$ wind $(\mathrm{m} / \mathrm{s})$ & Uniform & $1.800 \mathrm{E} 0$ & $3.800 \mathrm{E} 0$ & $2.800 \mathrm{E} 0$ \\
\hline$\sigma$ wind_dir $\left({ }^{\circ}\right)$ & Uniform & $-1.000 \mathrm{E} 1$ & $1.000 \mathrm{E} 1$ & $0.000 \mathrm{E} 0$ \\
\hline$\sigma$ current $(\mathrm{m} / \mathrm{s})$ & Uniform & $-5.000 \mathrm{E}-2$ & $5.000 \mathrm{E}-2$ & $0.000 \mathrm{E} 0$ \\
\hline$\sigma$ current_dir $\left(^{\circ}\right)$ & Uniform & $-1.000 \mathrm{E} 1$ & $1.000 \mathrm{E} 1$ & $0.000 \mathrm{E} 0$ \\
\hline Angle $\left(^{\circ}\right)$ & & $4.500 \mathrm{E} 1$ & $1.800 \mathrm{E} 2$ & Variable \\
\hline
\end{tabular}

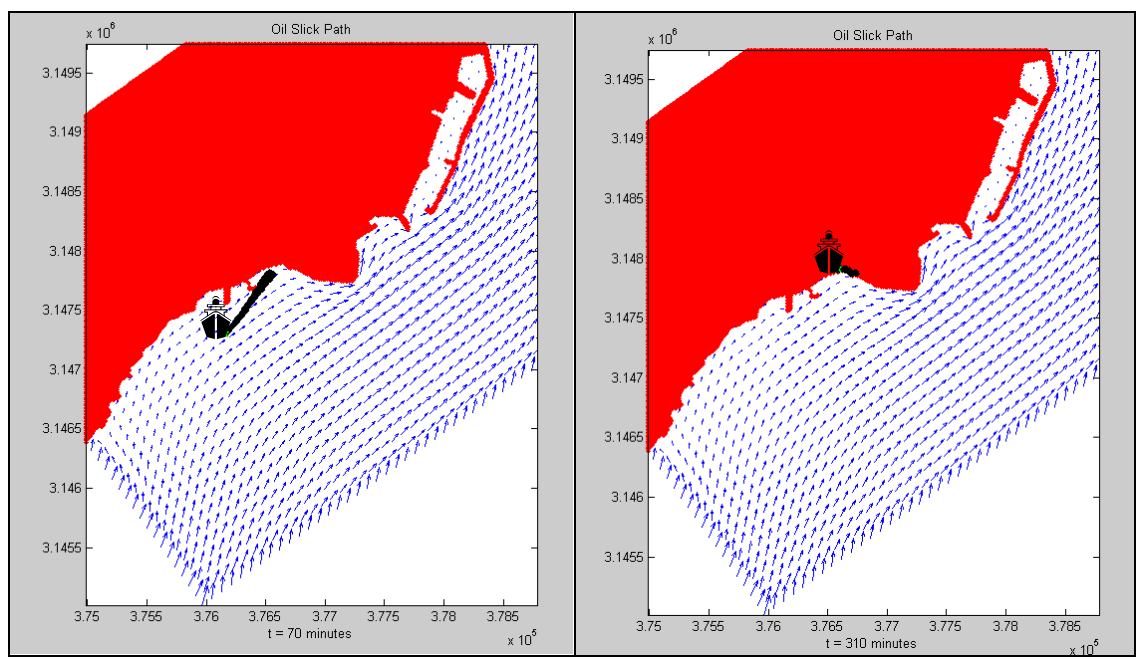

Figure 4: Slick path corresponding to the fitness obtained using the FEA with 100 generations on each of 10 individuals: $f(x)=197.182 \mathrm{~m}$ with $x=55.58^{\circ}$. In addition, the mean values of Table 1 are considered.

In order to solve the robust design optimisation any efficient optimisation algorithm can be used. Evolutionary algorithms are among the most efficient optimisation algorithms at solving real life problems and among them, here, we use our optimizer named Flexible Evolution Agent (FEA) [2, 3] that has the capacity to adapt the operators, the parameters and the algorithm to the circumstances faced at each step of every optimisation run. 
Due to the fact that the FEA is a mono-objective optimisation algorithm and here we have two objectives to minimise, the following weight function was considered as the fitness function to minimize:

$$
g(\bar{x})=\bar{f}(\bar{x})+10^{-3} \sigma(\bar{x})
$$

In Fig. 4 we can see the fitness obtained using the FEA with 100 generations on each of 10 candidate solutions (often called in evolutionary algorithms 'individuals' or 'chromosomes'), but without Robust Design: $f(x)=197.182 \mathrm{~m}$. The solution appeared at generation 70 and it corresponds to a course (direction) to be considered by the damaged tanker of $55.58^{\circ}$. In addition, the mean values of Table 1 are considered. In Fig. 5 we can see a solution (in this case wind direction $=10^{\circ}$ ) that is very similar to the one shown in Fig. 4, but with a very different objective function value: $f(x)=364.230 \mathrm{~m}$.

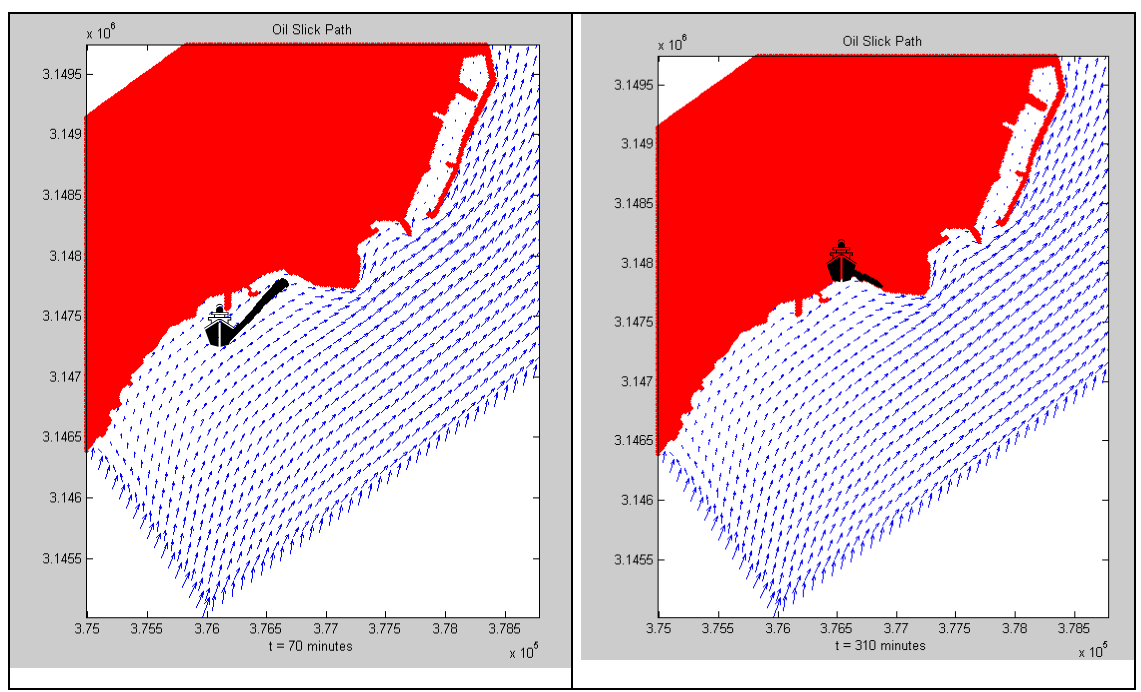

Figure 5: Slick path associated with an individual with the same course (direction) as the fitness shown in Fig. 1 but with a wind direction of $10^{\circ}$.

In Fig. 6 and 7 we can see the mean and standard deviation value histories applying Robust Design Optimization. It is possible to observe how a clear convergence has been obtained, with the optimisation goals being achieved. There is a remarkable correspondence between the mean and the standard deviation as can be observed in Fig. 8, where the scatter plot between the two functions is shown. 


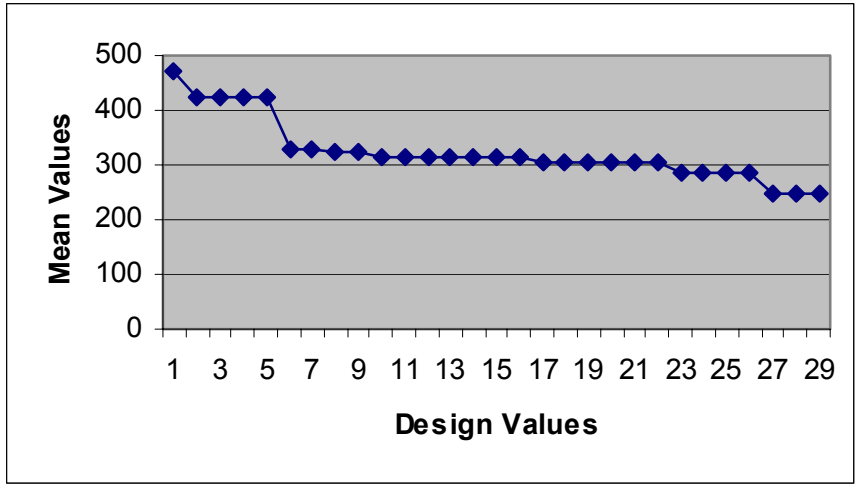

Figure 6: Mean value history.

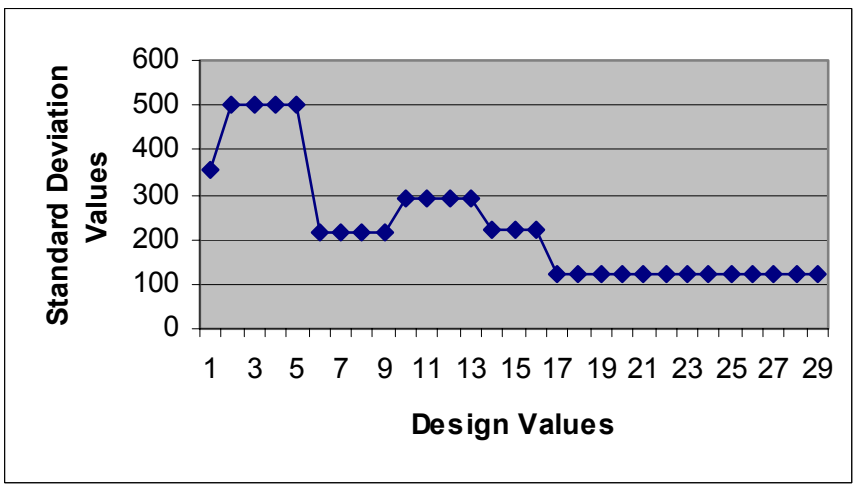

Figure 7: Standard deviation value history.

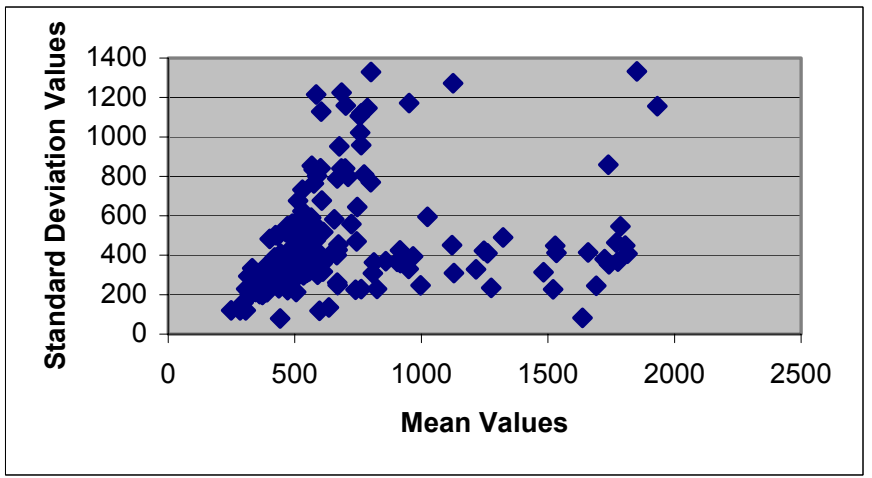

Figure 8: $\quad$ Scatter plot between mean and standard deviation of length coastal affected by spilled oil. 
The best solution was found in the FEA generation 27 with course $51.6258^{\circ}$ East: fitness value $=248.945891$; mean value $=248.82576$ and standard deviation value $=120.131073$. The robust solution set associated with this fitness is shown in the following table:

Table 2 .

\begin{tabular}{|c|c|c|c|c|c|}
\hline & $\sigma$ wind_dir $\left({ }^{\circ}\right)$ & $\sigma$ wind $(\mathrm{m} / \mathrm{s})$ & $\sigma$ current_dir $\left({ }^{\circ}\right)$ & $\sigma$ current $(\mathrm{m} / \mathrm{s})$ & $f(x)$ \\
\hline & 7.405589 & 0.929846 & -0.94992 & 0.030195 & 157.847005 \\
\hline & -7.405589 & -0.929846 & 0.94992 & -0.030195 & 217.211446 \\
\hline & 0.246547 & -0.018433 & -5.243893 & -0.024797 & 162.757522 \\
\hline & -0.246547 & 0.018433 & 5.243893 & 0.024797 & 171.424577 \\
\hline & 2.59957 & -0.374406 & 4.8316 & 0.001798 & 188.189699 \\
\hline & -2.59957 & 0.374406 & -4.8316 & -0.001798 & 402.433096 \\
\hline & 3.617779 & 0.228536 & 9.650865 & -0.042217 & 445.616903 \\
\hline & -3.617779 & -0.228536 & -9.650865 & 0.042217 & 510.227986 \\
\hline & -7.371967 & 0.38604 & -2.762191 & 0.037691 & 177.692337 \\
\hline & 7.371967 & -0.38604 & 2.762191 & -0.037691 & 154.208938 \\
\hline & -7.744379 & 0.880482 & -9.190978 & 0.04502 & 193.814169 \\
\hline & 7.744379 & -0.880482 & 9.190978 & -0.04502 & 186.508067 \\
\hline & -3.572945 & 0.444966 & -0.376189 & 0.046946 & 177.692337 \\
\hline & 3.572945 & -0.444966 & 0.376189 & -0.046946 & 175.133888 \\
\hline & -5.118267 & 0.776665 & 8.56454 & 0.034409 & 472.669669 \\
\hline & 5.118267 & -0.776665 & -8.56454 & -0.034409 & 171.424577 \\
\hline & 3.511946 & 0.510178 & -1.252708 & 0.027558 & 171.424577 \\
\hline & -3.511946 & -0.510178 & 1.252708 & -0.027558 & 397.580039 \\
\hline & 5.65087 & 0.071271 & -3.929351 & -0.000149 & 216.207845 \\
\hline & -5.65087 & -0.071271 & 3.929351 & 0.000149 & 226.450598 \\
\hline Mean & 0.000000 & 0.000000 & 0.000000 & 0.000000 & 248.82576 \\
\hline $\begin{array}{r}\text { Standard } \\
\text { Deviation }\end{array}$ & 5.353795 & 0.566448 & 5.871340 & 0.033884 & 120.131076 \\
\hline
\end{tabular}

\section{Conclusions}

In this paper we have solved a robust optimisation problem of practical interest concerning the minimization of coastal environmental impacts from oil spills. We have presented a methodology and results aimed at helping spill decision responders to take an appropriate decision to minimize coastal environmental impact by means of finding the optimal course of a damaged tanker leaking oil into the sea. 


\section{Acknowledgments}

We wish to thank Dr. Jacques Périaux, Dr. Carlo Poloni and Dr. Valentino Pediroda for the help and advice given to CEANI in the application of the Robust Design in environmental problems such as that dealt with in this paper.

\section{References}

[1] Integrated network of monitoring, alert and risk management of contaminating spills and catastrophic incidents in the Macaronesian maritime zone (ALERMAC); Interreg IIIB project; Ref. 03/MAC/4.2/C6, 2004-2006.

[2] Winter G., Galván B., Alonso S., González B., Evolving from Genetic Algorithms to Flexible Evolution Agents, Late Breaking Papers GECCO 2002, pp. 466-473, 2002.

[3] Winter, G., Galván, B., Alonso, S., González, B., Jiménez, J.I., Greiner, D., Flexible Evolutionary Algorithms: cooperation and competition among real-coded evolutionary operators, Soft Computing - A Fusion of Foundations, Methodologies and Applications, 9 (4), pp. 299-323, Springer-Verlag, 2004.

[4] Egorov, I.N., Kretinin, G.V., Leshchenko, I.A. and Kuptzov, S.V., Multiobjective robust design optimization using IOSO technology algorithms. Evolutionary algorithms and intelligent tools in engineering optimization, W. Annicchiarico, J. Périaux, M. Cerrolaza and G. Winter (Eds.), CIMNE, Barcelona, Spain 2005.

[5] http://www.gtk.fi/projects/espon/Env_Risk_finalreport.pdf

[6] Fundación Puertos de Las de Palmas. http://www.fundacionpuertos.com/

[7] Winter G., González B., Benítez E., Galván B., et al., CEANI Report on Evolution of the Oil Slicks and Evaluation of the Coastal Environmental Impacts, 2005.

[8] Stolzenbach, K.D., Madsen, O.S., Adams, E.E., Pollack, A.M., Cooper, C.K. A review and evaluation of basic techniques for predicting the behavior of surface oil slicks, Report No. 22, MIT: Cambridge, Mass. USA, 1977.

[9] Fay, J.A. The spread of oil slicks on a calm sea. Fluid Mechanics Laboratory, Dept. of Mech. Eng., MIT: Cambridge, MA, USA, 1969.

[10] Flores, H., Andreatta, A., Llona, G. and Saavedra, I., Measurements of oil spill spreading in a wave tank using digital image processing. Oil and hydrocarbon spills, modeling, analysis and control, WIT Press, Southampton, UK, pp. 165-173, 1998.

[11] Leitão, P., Modelo de dispersão lagrangeano tridimensional, dissertaçao de mestrado, Instituto Superior Técnico, Universidade Técnica de Lisboa, Lisboa, 1996.

[12] Proctor, R., Flather, R.A., Elliot, A.J., Modelling tides and surface drift in the Arabian Gulf, application to de Gulf oil spill. Continental Shelf Res 1, pp. 531-545, 1994. 
272 Water Pollution VIII: Modelling, Monitoring and Management

[13] Fingas, M.F., Modeling evaporation using models that are not boundarylayer regulated, Journal of Hazardous Materials, 107, pp 27-36, 2004.

[14] Fingas, M.F. and Fieldhouse, B., Formation of water-in-oil emulsions and application to oil spill modelling, Journal of Hazardous Materials, 107, pp 37-50, 2004.

[15] Law, A. W.-K., Findikakis, A.N., Cheng, N.-S., Oil Transport in Surf Zone, Journal of Hydraulic Engineering, 126 (11), pp. 803-809, 2000. 